\title{
Effect of anti-caking agents on moisture sorption isotherms of palmyra-palm jaggery granules
}

\author{
- P.V. K. Jagannadha RaO ${ }^{*}$, MAdhusweta DAS ${ }^{2}$ and S. K. DAS ${ }^{2}$ \\ ${ }^{1}$ All India Co-ordinated Research Project on Post-Harvest Technology, Regional Agricultural Research Station, ANAKAPALLI \\ (A.P.) INDIA \\ ${ }^{2}$ Department of Agricultural and Food Engineering, Indian Institute of Technology, KHARAGPUR (W.B.) INDIA \\ Email:pvkjrao@rediffmail.com;pvkjrao@gmail.com
}

*Author for Correspondence

Research chronicle : Received : 31.10.2017; Revised : 10.11.2017; Accepted : 24.11.2017

SUMMARY :

Jaggery granules, prepared from palmyra-palm syrup, were mixed with five levels $(0.5$ to $2 \% \mathrm{w} / \mathrm{w})$ of anti-caking agents [tri calcium phosphate, (TCP) or corn starch (CS)] and their moisture sorption isotherms were determined without or with addition of anticaking agents by the static equilibrium method using saturated salt solutions at four temperatures of 25,35 and $45 \mathrm{C}$. The moisture sorption isotherms for this granular jaggery samples are Type-III isotherms and the effect of temperature on equilibrium moisture content (EMC) values upto a water activity values of 0.3 to 0.5 show no significant effect. Among two moisture sorption isotherms (MSI) models tested with the experimental data for this high sugar food, GAB model was found to be the best fit followed by Iglesias and Chirife model. The monolayer moisture content $\left(\mathrm{M}_{0}\right)$ of the granular jaggery samples varied from a minimum of $4.195 \%$ (d.b.) for the granulated jaggery without anticaking agent at $45^{\circ} \mathrm{C}$ to a maximum of $7.303 \%$ (d.b.) for granulated jaggery with TCP and 9.178\% (d.b.) for granulated jaggery with corn starch @ 2.0\% at a temperature of $25^{\circ} \mathrm{C}$. A decreasing trend for both Mo and $\mathrm{C}$ values but increasing trend for $\mathrm{K}$ was obtained with the increase in temperature. The monolayer moisture content of jaggery granules with addition of TCP or CS has been found to posses good correlation with temperature. The net isosteric heat of sorption $\left(\mathrm{q}_{\mathrm{st}}\right)$ of jaggery granules without addition of anticaking agents, decreased exponentially from 29.132 to $4.833 \mathrm{~kJ} \mathrm{~mol}^{-1}$ with the increase in moisture content from 2.5 to $15 \%$ (d.b.). It was also observed that, net isosteric heat of sorption was found to be higher for the jaggery granules without addition of anti-caking agents as compared to samples with addition of anti-caking agents.

KEY WORDS : Jaggery, Palmyra-palm, Palm juice, Anti-caking agents, Moisture sorption isotherm, Water activity, Net isosteric heat of sorption

How to cite this paper : Rao, P.V. K. Jagannadha, Das, Madhusweta and Das, S.K. (2017). Effect of anticaking agents on moisture sorption isotherms of palmyra-palm jaggery granules. Internat. J. Proc. \& Post Harvest Technol., 8 (2) : 113-122. DOI: 10.15740/HAS/IJPPHT/8.2/113-122. 